\title{
Estimation The Scavenging Activities of Ascorbic Acid, Uric Acid, Gallic Acid and GSH to DPPH Radical
}

\author{
Ali M.A. Al-Kufaishi \\ Al-Furat Al-Awsat Technical University College of Health and Medical Techniques, Department of Medical \\ Laboratory Techniques, Kufa, Iraq
}

\begin{abstract}
The " $\alpha, \alpha$-diphenyl- $\beta$-picrylhydrazyl radical (DPPH)" method from the estimation methods to determine the antioxidants activity in vitro, through the lowering the absorbance of DPPH with color changing from violet into yellow with increasing the strength of antioxidants activity. So, the results of this study show the uric acid is the strongest scavenging, then ascorbic acid when compared with other compounds used. But the reduced glutathione is the weakest although has acidic hydrogen.
\end{abstract}

Keywords: DPPH, scavenging activity, antioxidants, Ascorbic Acid, Uric Acid, Gallic Acid.

\section{Introduction}

The efficiency of antioxidants (scavenging activity) depends on the ability of free radicals scavengers (FRS) to given hydrogen to the free radicals ${ }^{(1)}$. The increase in rate and energy promotion for hydrogen ion transition from FRS to free radicals depend on the lowering in energy level for hydrogen bond with FRS. Efficient FRS results free radicals after donating hydrogen but not react rapidly with oxygen to produce superoxide. The efficiency of FRS as well depends on other factors as volatility, $\mathrm{pH}$ sensitivity and polarity ${ }^{(2)}$.

In the present study, the antioxidants involve such as vitamin $\mathrm{C}$, uric acid, gallic acid, and reduced glutathione.

\section{Ascorbic acid (AA):}

One from most powerful FRS ${ }^{(3,4)}$. It is found in several plants cells types. AA present in the reduced form under physiological conditions $(90 \%$ of the ascorbate pool) in plants leaves and chloroplasts (5), were the concentration of AA $(20 \mathrm{mM})$ in the cytosol, and $(20-200 \mathrm{mM})$ in the chloroplast stroma ${ }^{(6)}$. The ability of AA to give the electron by many enzymatic and nonenzymatic reactions, therefore act as main detoxification antioxidants against ROS in the aqueous phase. So, the AA can directly be scavenging for singlet oxygen, superoxide radical, hydroxyl radical and reduced hydrogen peroxide to water by ascorbate peroxidase reaction ${ }^{(7)}$.

AA capable to reduce tocopheroxyl radical into tocopherol that responsible about cell membrane protection. AA performs a number of non-antioxidant roles in the cells. It has been involved in the regulation of cell cycle progression from G1 to S phase, cell division, and cell elongation ${ }^{(8,9)}$.

\section{Glutathione (GSH):}

"Tripeptide glutathione ( $\square$ glutamylcysteinylglycine)" is a plentiful compound in the tissues of plants. It is found in all compartments of the cell such as cytosol, mitochondria, and endoplasmic reticulum (10), were GSH has many roles in organisms such as storage for the sulphur, serve as precursors for phytochelatins, act as a detoxifier for xenobiotics via GSH-conjugation $(11,12)$, and maintenance about redox form of the cellular membrane through (GSH-GSSG) system. Also, GSH has the ability to regulate gene expression. And regulation of cell cycle by GSH/GSSG system through -SH group $(13,14)$.

GSH act as antioxidants through the nucleophilic center of $-\mathrm{SH}$ residue that responsible for higher reductive potential. So, its scavenger for singlet oxygen, 
superoxide radical and hydroxyl radical by nonenzymatic reactions, and with hydrogen peroxide and reducing to water by an enzymatic reaction ${ }^{(15)}$. GSH has the ability to regenerate others antioxidants such ascorbic acid through the ascorbate-glutathione cycle $(16,17)$.

\section{Uric Acid (UA):}

The final product of purine degradation in human and "Great Apes". It is a powerful scavenger for free radical such as singlet oxygen, hydroxyl radicals $(. \mathrm{OH})$, and peroxyl radicals (RO. 2) ${ }^{(18,19)}$. In blood, stream urate considers from the major antioxidants against oxidative damage, so it is protected RBCs membrane from lipids peroxidation by scavenging oxygen radicals in aqueous media ${ }^{(20)}$. Uric acid some of the deleterious reactions, such as peroxide production by macrophages or autoxidation of haemoglobin ${ }^{(21)}$.

In contrast, elevated the UA causes a lot of number from the epidemiology of hypertension (22), cardiovascular disease (23), visceral obesity (24), dyslipidemia ${ }^{(25)}$, insulin resistance ${ }^{(26)}$, kidney disease (19).

Gallic Acid (GA):

"GA is a 3,4,5-trihydroxybenzoic acid and its derivatives are widely spread in the plant kingdom and is a large family from secondary polyphenolic metabolites" in plants so it is from natural antioxidants (27). GA present either methylated gallic acid form such as syringic acid, or in the orgalloyl conjugated form with catechin derivatives as "flanvan-3-ols, or in polygalloyl esters" form with glycerol, quinic acid or glucose ${ }^{(28)}$.

The last two groups from "polyphenols are known as vegetable tannins, which their names derived from its ability to transform animal skins into leather" through the with collagen ${ }^{(29)}$. GA from the components of tea and some types of GA used as food additives to prevent peroxidation. Also, it is used in many phytomedicines due to its biological and pharmacological activities through the ability to free radicals scavenger (30), inducing apoptosis for the cancer cells ${ }^{(31,32)}$, and inhibiting squalene epoxidase interfering the signal pathways involving calcium ${ }^{(33,34)}$.

\section{$\alpha, \alpha$-diphenyl- $\beta$-picrylhydrazyl radical (DPPH):}

DPPH is described as relatively stable free radical due to delocalization phenomenon for the unshared electron overall whole molecule, so this radical do not suffer from dimerization as other radicals. The delocalization gives this radical the deep violet color when dissolved in absolute ethanol and absorbed at 517 $\mathrm{nm}$. DPPH used to estimation the antioxidants activity for any sample or free radicals scavenging material ${ }^{(35)}$.

\section{Material and Methods:}

\section{Prepared Serial Solutions:}

\section{Prepared Ascorbic acid solutions:}

This is done by dissolving ascorbic acid in distilled water (D.W.) as the following concentrations: $2.5,5,10$, $15,20,25,30,35,40,45,50,55,60,65,70 \mathrm{mg} / \mathrm{dl}$.

\section{Prepared GSH solutions:}

This is done by dissolving GSH in distilled water (D.W.) as the following concentrations: $2.5,5,10,15$, $20,25,30,35,40,45,50,55,60,65,70 \mathrm{mg} / \mathrm{dl}$.

\section{Prepared UA solutions:}

This is done by dissolving UA in distilled water (D.W.) ( $\mathrm{pH} \mathrm{8.5)} \mathrm{as} \mathrm{the} \mathrm{following} \mathrm{concentrations:} \mathrm{2.5,} \mathrm{5,}$ $10,15,20,25,30,35,40,45,50,55,60,65,70 \mathrm{mg} / \mathrm{dl}$.

\section{Prepared GA solutions:}

This is done by dissolving GA in absolute ethanol as the following concentrations: $2.5,5,10,15,20,25,30$, $35,40,45,50,55,60,65,70 \mathrm{mg} / \mathrm{dl}$.

\section{DPPH procedure:}

\section{DPPH preparation:}

Prepared $0.1 \mathrm{mM}$ from DPPH, by dissolving appropriate weight in absolute ethanol.

\section{Principle of method:}

The principle of this method depends on the reduce the absorbance values of DPPH after addition the sample due to conversion the violet colour into yellow colour depending on the antioxidants activity of the sample. 
The colour intensity measured at $517 \mathrm{~nm}$ (36) (figure 1).

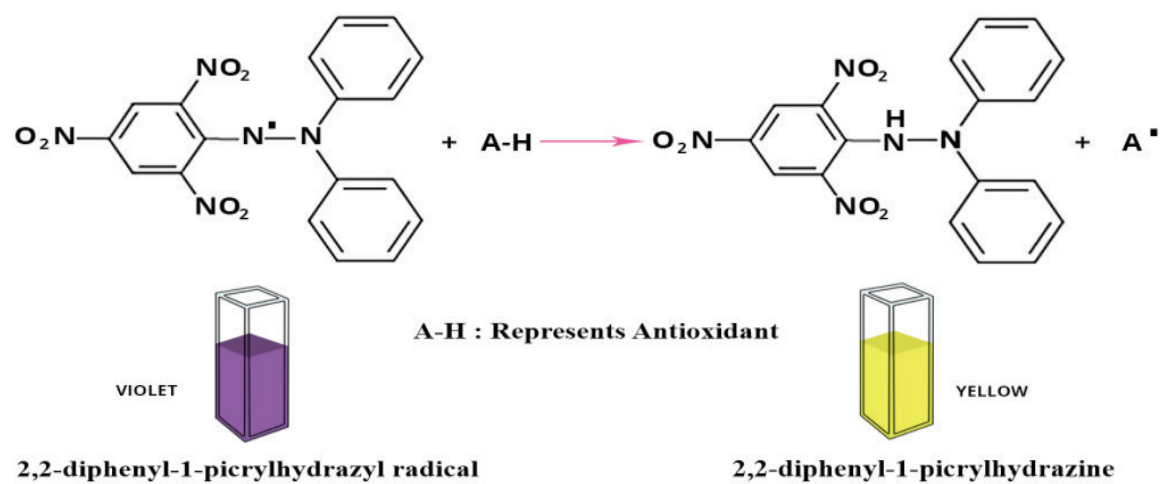

Fig. 1: Reduction effect of AH to DPPH.

Procedure: The procedure of addition as following:

\begin{tabular}{|c|c|c|}
\hline Reagent & Sample/ $\mu \mathrm{l}$ & 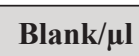 \\
\hline DPPH & 1000 & 1000 \\
\hline Sample & 100 & ------- \\
\hline D.W. & ------ & 100 \\
\hline
\end{tabular}

Incubate for $20 \mathrm{~min}$ at $25^{\circ} \mathrm{C}$. In the dark condition, then read the absorbance at $517 \mathrm{~nm}$.

\section{Results and Discussion}

The following results (Table 1) and (Figure 2) the inhibition values of DPPH by the antioxidants compounds. In other words, the absorption values for DPPH after scavenging by ascorbic acids, GSH, UA, and GA.

Table 1: Absorption values for DPPH after scavenging by UA, GA, GSH, and ascorbic acid.

\begin{tabular}{|l|l|l|l|l|}
\hline $\begin{array}{l}\text { Concentration (mg/dl) of U.A, Gallic } \\
\text { acid, GSH, Ascorbic acid }\end{array}$ & UA & Gallic acid & GSH & Ascorbic acid \\
\hline 2.5 & 0.302 & 0.323 & 0.352 & 0.314 \\
\hline 5 & 0.289 & 0.321 & 0.352 & 0.292 \\
\hline 10 & 0.280 & 0.320 & 0.351 & 0.288 \\
\hline 15 & 0.275 & 0.315 & 0.344 & 0.286 \\
\hline 20 & 0.269 & 0.311 & 0.344 & 0.280 \\
\hline 25 & 0.259 & 0.310 & 0.344 & 0.279 \\
\hline 30 & 0.251 & 0.303 & 0.343 & 0.274 \\
\hline 35 & 0.247 & 0.291 & 0.343 & 0.268 \\
\hline 40 & 0.243 & 0.290 & 0.343 & 0.261 \\
\hline 45 & 0.238 & 0.289 & 0.332 & 0.254 \\
\hline 50 & 0.211 & 0.262 & 0.332 & 0.238 \\
\hline 55 & 0.193 & 0.249 & 0.332 & 0.226 \\
\hline 60 & 0.169 & 0.232 & 0.332 & 0.212 \\
\hline 65 & 0.145 & 0.221 & 0.332 & 0.195 \\
\hline 70 & 0.123 & 0.214 & 0.332 & 0.185 \\
\hline
\end{tabular}




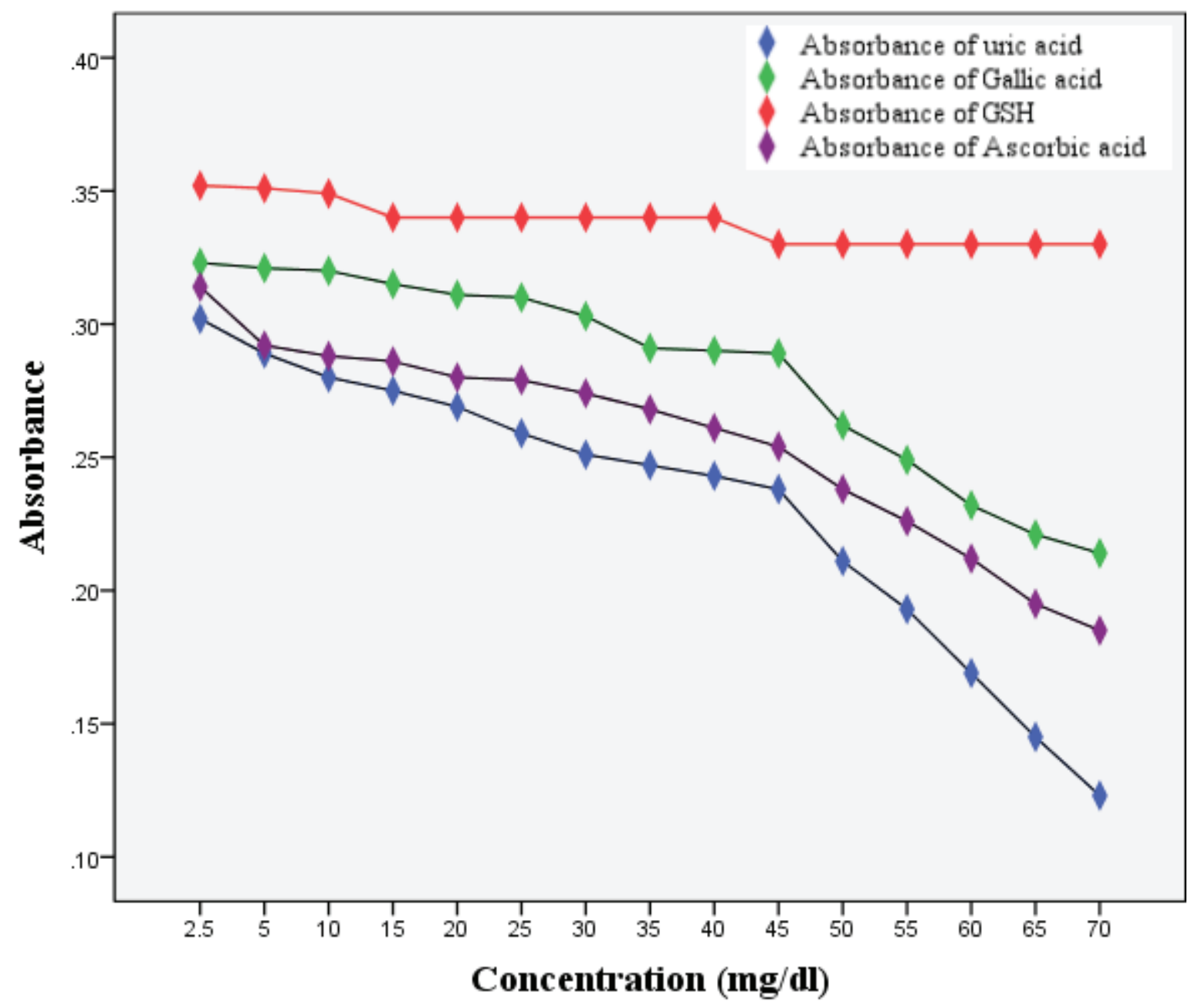

Fig. 2: Decline in absorption values for DPPH after scavenging by UA, GA, GSH, and ascorbic acid.

The scavenging effect for UA toward DPPH is more than other antioxidants were used in this study when compared in the same concentrations, may be due to the heterocyclic ring effect that responsible about delocalization and lowering energy of hydrogen bond with the compound (figure 3).

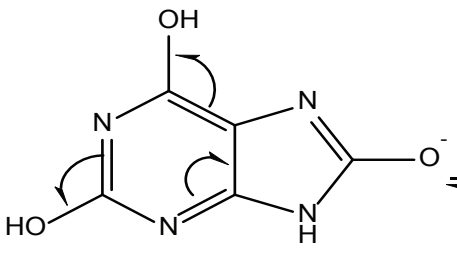

Urate ion<smiles></smiles>

lactim form<smiles>O=c1[nH]c(=O)c2[nH]c(=O)[nH]c2[nH]1</smiles>

lactam form

Fig. 3: Urate tautomerism

From the results show a slight decrease in the line chart (figure 2) for the GSH value, this means it is the weakest scavenging compared with other compounds used in this study may be due to the energy bond of hydrogen in the thiol group is relatively strongest than other compounds, therefore no change in the color of DPPH. However, the scavenging effect increased with an increase in concentrations of these antioxidants compounds.

Conclusion: 
In conclusion, the strongest scavenging in vitro the compounds that have the ability to reduce the DPPH and change its the color from violet into yellow, therefore the scavenging strength follow the sequence UA, AA, and GA, where the GSH is very weakest scavenging to $\mathrm{DPPH}$ at the same concentrations.

Ethical Clearance: The Research Ethical Committee at scientific research by ethical approval of both environmental and health and higher education and scientific research ministries in Iraq

Conflict of Interest: The authors declare that they have no conflict of interest.

Funding: Self-funding

\section{References}

1. Al-kufaishi AMA. The-effect-of-garlic-vinegar-onthe-blood-of-patients-with-high-blood-viscosity. docx. IJSER. 2015;6(7):2005-20.

2. Lee JH, Ozcelik B, Min DB. Electron donation mechanisms of $\beta$-carotene as a free radical scavenger. J Food Sci. 2003;68(3):861-5.

3. Bagni N. the Function and Metabolism of Polyamines in Plants. Ann Bot. 2015;78:661-9.

4. Arrigoni O, De Tullio MC. The role of ascorbic acid in cell metabolism: between gene-directed functions and unpredictable chemical reactions. J Plant Physiol. 2000;157(5):481-8.

5. Smirnoff N. Ascorbic acid: metabolism and functions of a multi-facetted molecule. Curr Opin Plant Biol. 2000;3(3):229-35.

6. Foyer $\mathrm{CH}$, Lelandais $\mathrm{M}$. A comparison of the relative rates of transport of ascorbate and glucose across the thylakoid, chloroplast and plasmalemma membranes of pea leaf mesophyll cells. J Plant Physiol. 1996;148(3-4):391-8.

7. Noctor G, Foyer $\mathrm{CH}$. Ascorbate and glutathione: keeping active oxygen under control. Annu Rev Plant Biol. 1998;49(1):249-79.

8. De Tullio MC, Paciolla C, Dalla Vecchia F, Rascio N, D'Emerico S, De Gara L, et al. Changes in onion root development induced by the inhibition of peptidyl-prolyl hydroxylase and influence of the ascorbate system on cell division and elongation. Planta. 1999;209(4):424-34.

9. Liso R, Innocenti AM, Bitonti MB, Arrigoni O.
Ascorbic acid $\square$ induced progression of quiescent centre cells from G1 to S phase. New Phytol. 1988;110(4):469-71.

10. Jiménez A, Hernández JA, Pastori G, del Rio LA, Sevilla F. Role of the ascorbate-glutathione cycle of mitochondria and peroxisomes in the senescence of pea leaves. Plant Physiol. 1998;118(4):1327-35.

11. Noctor G, Arisi A-CM, Jouanin L, Kunert $\mathrm{KJ}$, Rennenberg H, Foyer CH. Glutathione: biosynthesis, metabolism and relationship to stress tolerance explored in transformed plants. J Exp Bot. 1998;49(321):623-47.

12. May MJ, Vernoux $T$, Leaver C, Montagu M Van, Inzé D. Glutathione homeostasis in plants: implications for environmental sensing and plant development. J Exp Bot. 1998;49(321):649-67.

13. Wingate VPM, Lawton MA, Lamb CJ. Glutathione causes a massive and selective induction of plant defense genes. Plant Physiol. 1988;87(1):206-10.

14. SAnchez-FERNAndez Roci, Fricker M, Corben LB, White NS, Sheard N, Leaver CJ, et al. Cell proliferation and hair tip growth in the Arabidopsis root are under mechanistically different forms of redox control. Proc Natl Acad Sci. 1997;94(6):274550.

15. Larson RA. The antioxidants of higher plants. Phytochemistry. 1988;27(4):969-78.

16. Foyer $\mathrm{CH}$, Halliwell $\mathrm{B}$. The presence of glutathione and glutathione reductase in chloroplasts: a proposed role in ascorbic acid metabolism. Planta. 1976;133(1):21-5.

17. Noctor G, Arisi A-CM, Jouanin L, Foyer CH. Manipulation of glutathione and amino acid biosynthesis in the chloroplast. Plant Physiol. 1998;118(2):471-82.

18. Alper Jr AB, Chen W, Yau L, Srinivasan SR, Berenson GS, Hamm LL. Childhood uric acid predicts adult blood pressure: the Bogalusa Heart Study. Hypertension. 2005;45(1):34-8.

19. Johnson RJ, Kang D-H, Feig D, Kivlighn S, Kanellis $\mathrm{J}$, Watanabe S, et al. Is there a pathogenetic role for uric acid in hypertension and cardiovascular and renal disease? Hypertension. 2003;41(6):1183-90.

20. Kellogg EW, Fridovich I. Liposome oxidation and erythrocyte lysis by enzymically generated superoxide and hydrogen peroxide. J Biol Chem. 1977;252(19):6721-8. 
21. Frei B, Stocker R, Ames BN. Antioxidant defenses and lipid peroxidation in human blood plasma. Proc Natl Acad Sci. 1988;85(24):9748-52.

22. Johnson RJ, Segal MS, Srinivas T, Ejaz A, Mu W, Roncal C, et al. Essential hypertension, progressive renal disease, and uric acid: a pathogenetic link? J Am Soc Nephrol. 2005;16(7):1909-19.

23. Alderman $\mathrm{MH}$, Cohen $\mathrm{H}$, Madhavan S, Kivlighn S. Serum uric acid and cardiovascular events in successfully treated hypertensive patients. Hypertension. 1999;34(1):144-50.

24. Ogura T, Matsuura K, Matsumoto Y, Mimura Y, Kishida M, Otsuka F, et al. Recent trends of hyperuricemia and obesity in Japanese male adolescents, 1991 through 2002. Metabolism. 2004;53(4):448-53.

25. Nakanishi N, Okamoto M, Yoshida H, Matsuo Y, Suzuki K, Tatara K. Serum uric acid and risk for development of hypertension and impaired fasting glucose or Type II diabetes in Japanese male office workers. Eur J Epidemiol. 2003;18(6):523-30.

26. Zavaroni I, Mazza S, Fantuzzi M, Dall'Aglio E, Bonora E, Delsignore R, et al. Changes in insulin and lipid metabolism in males with asymptomatic hyperuricaemia. J Intern Med. 1993;234(1):25-30.

27. Tang HR, Covington AD, Hancock RA. Structureactivity relationships in the hydrophobic interactions of polyphenols with cellulose and collagen. Biopolym Orig Res Biomol. 2003;70(3):403-13.

28. Tang HR, Covington AD, Hancock RA. Synthesis and spectroscopic characterisation of the polygalloyl esters of polyols-models for gallotannins. J Soc Leather Technol Chem. 2003;87(5):179-88.
29. Tang HR, Covington AD, Hancock RA. Use of DSC to detect the heterogeneity of hydrothermal stability in the polyphenol-treated collagen matrix. J Agric Food Chem. 2003;51(23):6652-6.

30. Kanai S, Okano H. Mechanism of the protective effects of sumac gall extract and gallic acid on the progression of CCl4-induced acute liver injury in rats. Am J Chin Med. 1998;26(03n04):333-41.

31. Sakagami H, Satoh K, Hatano T, Yoshida T, Okuda $\mathrm{T}$. Possible role of radical intensity and oxidation potential for gallic acid-induced apoptosis. Anticancer Res. 1997;17(1A):377-80.

32. Saeki K, Yuo A, Isemura M, ABE I, SEKI T, NOGUCHI H. Apoptosis-inducing activity of lipid derivatives of gallic acid. Biol Pharm Bull. 2000;23(11):1391-4.

33. Abe I, Seki T, Noguchi H. Potent and selective inhibition of squalene epoxidase by synthetic galloyl esters. Biochem Biophys Res Commun. 2000;270(1):137-40.

34. Inoue M, Sakaguchi N, Isuzugawa K, TANI H, OGIHARA Y. Role of reactive oxygen species in gallic acid-induced apoptosis. Biol Pharm Bull. 2000;23(10):1153-7.

35. Molyneux P. The use of the stable free radical diphenylpicryl- hydrazyl (DPPH) for estimating antioxidant activity. J Sci Technol. 2004;26(2):2119.

36. Singh N, Rajini PS. Free radical scavenging activity of an aqueous extract of potato peel. Food Chem. 2004;85:611-6. 